\title{
Quality of the Tuberculosis Control Program, Havana, Cuba, 2018
}

\author{
Donelia Gamez Sanchez ${ }^{1,}$, , Leidis Margarita Perez Perez ${ }^{2}$, Odeite Dueñas Moreira ${ }^{1}$, \\ Maritza Benitez Martinez ${ }^{1}$, Dianellys Perez Jimenez ${ }^{1}$ \\ ${ }^{1}$ Hygiene, Epidemiology and Microbiology National Institute, La Habana, Cuba \\ ${ }^{2}$ Hygiene, Epidemiology and Microbiology Provincial Center, La Habana, Cuba \\ Email address: \\ gamezdone2018@gmail.com (D. G. Sanchez), leidisp69@nauta.cu (L. M. P. Perez), moreira@inhem.sld.cu (O. D. Moreira), \\ maritza.benitez@infomed.sld.cu (M. B. Martínez), dianellyspj@gmail.com (D. P. Jimenez) \\ ${ }^{*}$ Corresponding author
}

\section{To cite this article:}

Donelia Gamez Sanchez, Leidis Margarita Perez Perez, Odeite Dueñas Moreira, Maritza Benitez Martinez, Dianellys Perez Jimenez. Quality of the Tuberculosis Control Program, Havana, Cuba, 2018. Journal of Family Medicine and Health Care. Vol. 7, No. 2, 2021, pp. $26-29$. doi: $10.11648 /$ j.jfmhc.20210702.11

Received: April 9, 2021; Accepted: April 28, 2021; Published: May 15, 2021

\begin{abstract}
Background: Boyeros municipality is considered a high risk of tuberculosis, historically it maintains incidence rates above the provincial average. Objective: Evaluate the National Program for the Prevention and Control of Tuberculosis quality in Boyeros, 2018. Methods: a tactical evaluation was carried out according to components: structure, process and results. The universe constituted by 10 cases of tuberculosis notified during 2018 and 469 health workers who participated in the execution of the program. The information was obtained from the bibliographic and documentary review, the interview, observation and questionnaire. Summary measures such as absolute frequencies and percentage were used. Results: a deficit of doctors and nurses was found in the structure dimension, no update was carried out on the subject, $50 \%$ of the clinics did not have bottles, in $50 \%$ of the areas there was no availability of reagents, in the process dimension It did not comply with the indicators of second samples of sputum and cultures and in the results relapses and TB / HIV-AIDS co-infection were found. Conclusions: The lack of human and material resources, the lack of training on the subject, the failure to comply with the diagnostic times, the existence of relapses, loss of follow-up and TB / HIV co-infection, led to the evaluation of the National Program for the Control of Tuberculosis in the Boyeros municipality, during 2018 was evaluated as unsatisfactory, since the standards established for each dimension were not met.
\end{abstract}

Keywords: Tuberculosis, Evaluation, Structure Dimension, Process Dimension, Results

\section{Introduction}

Tuberculosis (TB) is an infectious disease of acute, subacute or chronic evolution whose presence has been constant in the history of humanity. In 1993 the World Health Organization (WHO) declared it as a disease in global emergency. He estimated that approximately eight million people fell ill annually from this cause, 1.1 million deaths and 350,000 deaths associated with HIV / AIDS infection. 95\% of tuberculosis deaths occurred in low- and middle-income countries, being one of the three leading causes of death in women between 15 and 44 years of age. This organization believes that if epidemiological control of the disease is not improved by 2020 , about 1 billion people will contract the infection. [1-3] It is estimated that the world could move towards eliminating tuberculosis if the support of governments aimed at the fight against poverty and growing inequality is maintained and strengthened, in addition to incorporating universal access to tuberculosis care in public health programs in general. [4-5]. TB notification rate in Cuba in 2018 was 5.8 x 100,000 inhabitants. La Havana Province, however, closed above the national average with $9.6 \times 100,000$ inhabitants and the Boyeros municipality reached a rate of $5.1 \times 100,000$ inhabitants, results that are paradoxical if one takes into account that the municipality is stratified as high risk and that has a historical behavior above even the national average. [6]. Cuba, in terms of prevention and control of this disease, met the goals set by the WHO for the year 2015 (detect $70 \%$ of new cases, cure $85 \%$ and of them guarantee treatment, 
maintain the sustainability of the Program National and have the political will to achieve it) that is why the current challenge is to achieve the elimination of tuberculosis in the country, for this a rate of 1 case per million inhabitants must be achieved. [7-8]. Several authors agree that program evaluation uses methods and techniques typical of social research, but it is an independent disciplinary field with specific objectives and challenges, such as the establishment of recommendations to improve programs and political negotiation. [9]. Boyeros municipality is considered a high-risk municipality, which historically maintains incidence rates above the provincial average, being one of the municipalities that drags the province in the negative results of the program, taking into account all the above, As well as the slow decrease in the incidence rate, the absence of previous studies published on the subject is that it is decided to carry out this research, in order to identify the existing gaps and provide new scientific knowledge for the adaptation of global strategies for put an end to tuberculosis as a health problem and improve the quality and health status of the population. Therefore, we propose as an objective: to evaluate the quality of the National Program for the Prevention and Control of Tuberculosis in Boyeros, 2018.

\section{Material and Methods}

A tactical health systems and services evaluation study was carried out through its components: structure, process and results.

The universe consisted of the total number of human resources that participated in the execution of the program in the 7 health areas that exist in the municipality, 10 new cases of tuberculosis, 190 family doctors and nurses, 32 laboratory technicians from the areas, 28 statisticians from the seven health areas, seven: health promoters, deputy directors of Hygiene and Epidemiology, specialists in Internal Medicine and specialists in Pediatrics.

The information was obtained from the bibliographic and documentary review, the interview, observation and questionnaire. Information sources: Interviews with deputy directors of hygiene and epidemiology and heads of human resources, case records from the statistics department, review of notifiable disease cards (EDO), prevalence cards from the statistics department, laboratory records, provincial and municipal databases, medical records of the cases reported in the family doctors' offices, treatment control cards and the epidemiological records of the reported cases.

Instruments validated by the National School of Public Health and used in tuberculosis evaluation studies in health areas of Havana were applied. The values of the chosen indicators were compared with the standards established by the program. Absolute and relative frequencies were used in the analysis. For the final evaluation of the program it was considered: Satisfactory: when the three dimensions were evaluated as acceptable. Unsatisfactory: when at least one of the dimensions (process or result) was evaluated as not acceptable or both, regardless of the result of the evaluation of the structure.

\section{Results}

In the structure dimension, of the 20 criteria evaluated, seven were insufficient, which represented $35 \%$, table 1 , medical and nursing coverage was not met in the seven health areas with $76.3 \%$ and $88.4 \%$. The existence of a deputy director of hygiene and epidemiology is breached in $57.1 \%$, epidemiologist coverage only reached $14.2 \%$.

Table 1. Evaluation of the structure. Boyeros Municipality. 2018.

\begin{tabular}{|c|c|c|c|c|}
\hline Criterion & No & $\%$ & Standart & Evaluation \\
\hline Family doctor coverage & 145 & 76.3 & $100 \%$ & Insufficient \\
\hline Family nurse coverage & 168 & 88.4 & $100 \%$ & Insufficient \\
\hline Existence of deputy director of hygiene and epidemiology & 4 & 57.1 & $100 \%$ & Insufficient \\
\hline Training on the subject for family doctors and nurses. & 0 & 0 & $100 \%$ & Insufficient \\
\hline Availability of flasks to carry out sputum. & 95 & 50 & 100 & Insufficient \\
\hline Availability of reagents for diagnosis. & 95 & 50 & $100 \%$ & Insufficient \\
\hline
\end{tabular}

Fuente. Plantilla de recursos humanos y materiales, dirección municipal de salud.

Training for family doctors and nurses was insufficient as it was found that there was no evidence in the last two years that training courses on the subject were held in the municipality.

The availability of bottles and reagents was insufficient, not complying with the established standard since only $50 \%$ was reached. The rest of the indicators were evaluated as sufficient.

General evaluation of the structure dimension in the municipality was insufficient for not complying with the proposed standard $(80 \%)$ for this dimension.

In the process dimension, 20 criteria were evaluated, of which $(55 \%)$ were considered unsuitable, table 2 , in all areas the indicator of $0.5 \%$ uptake of respiratory symptoms plus 21 days $(\mathrm{SR}+21)$ detected is not met in internal medicine, general medicine and pediatric consultations. The proportion of second samples was breached in $87.8 \%$. The proportion of cultures considered the gold standard for tuberculosis diagnosis was not met, reporting $82.0 \%$.

Cases must be notified in the first 48 hours after the patient is diagnosed, however in the study it was met in $10 \%$, that is, in only one case, related to a woman under 15 years of age, in the rest of the cases they were diagnosed in the past 48 hours. 
Table 2. Evaluation of the process activities. Boyeros Municipality, 2018.

\begin{tabular}{lllll}
\hline Criterion & No & Resultado \% & Standart & Evaluation \\
\hline Proportion of SR + 21 detected in consultations. & 189 & $0.2 \%$ & $0.5 \%$ & Not suitable \\
Proportion of second samples. & 166 & $87.8 \%$ & $90 \%$ & Not suitable \\
Proportion of crops grown. & 155 & $82.0 \%$ & $95 \%$ & Not suitable \\
Cases notified in a timely manner. & 1 & $10 \%$ & $<48$ horas & Not suitable \\
Proportion of epidemiological surveys completed correctly & 4 & $60 \%$ & $100 \%$ & Not suitable \\
Average number of contacts per case & 8 & 53,3 & 15 contactos & Not suitable \\
Time between 1st symptoms and consultation. & 42 días & & 30 días & Not suitable \\
Time between first symptoms and diagnosis of TB. & 80 & & 32 días & Not suitable \\
Time between diagnosis and start of treatment & 8 & $40 \%$ & 2 días & Not suitable \\
Duration of focus control. & 25 días & $0 \%$ & 15 días & Not suitable \\
TBp cases with positive smear microscopy diagnosed in APS. & 4 & $40 \%$ & $80 \%$ & Not suitable \\
\hline
\end{tabular}

Fuente. Bases de datos y Encuestas epidemiológicas de casos tuberculosis

The indicator of the time between the first symptoms and consultation is not met, exceeding 30 days, nor the time between diagnosis and start of treatment: it is only reached in $40 \%$ of cases. The duration of the outbreak controls was breached in all the diagnosed cases, lasting more than 25 days on average. Only $40 \%$ of the cases reported with positive smear microscopy were diagnosed in primary health care.
The evaluation of the process dimension was not adequate as it did not reach the established standard.

To evaluate the results dimension, 9 criteria were taken into account, of which 4 were evaluated as unsatisfactory, $44.4 \%$. Proportion of cured: in the same the program establishes that it must reach $90 \%$, however in the study only $30 \%$ was achieved, Table 3.

Table 3. Evaluation of results, Boyeros municipality, 2018.

\begin{tabular}{llll}
\hline Criterion & Result & Standard & Evaluation \\
\hline Proportion of Cured patients. & $30 \%$ & $90 \%$ & Not acceptable \\
Relapse Rate & $20 \%$ & Menos de 2\% & Not acceptable \\
Loss of follow-up & $30 \%$ & 0 & Not acceptable \\
Patients notified with TB / HIV-AIDS coinfection & $10 \%$ & 0 & Not acceptable \\
\hline
\end{tabular}

Fuente: Base de datos de la UMHE

The proportion of relapses reached $20 \%$, loss to follow-up $30 \%$, and according to the program it should be equal to or less than $2 \%$.

The evaluation of the result dimension was not acceptable as it did not reach the established standard of $80 \%$ of the criteria evaluated as acceptable. The existing gaps in compliance with the tuberculosis control program in the Boyeros municipality were evaluated as unsatisfactory, since out of a total of 49 criteria, $48.9 \%$ of them were unsatisfactory.

\section{Discussion}

When there are no doctors and nurses in $100 \%$ of the clinics, the execution of actions to control the focus of communicable diseases is committed, their presence and active leadership in the community being essential for better control and absolute control of the area and thus prevent their spread. [10] This result coincides with the study by Rosado et al., Who found that there was no availability of the binomial, $65.5 \%$ of medical coverage and $91.3 \%$ of nurses. [11] Unlike the results found in other studies, [12, 13] where human resources are evaluated as satisfactory. Failure to train human resources has a negative impact because what is not thought is not diagnosed and if the staff is not trained it is impossible for the disease to be diagnosed in a timely manner, if one takes into account that this program is subject to systematic updates according to behavior of the disease in the national and international context. This aspect could be related to the poor results achieved by the program in terms of late diagnosis of cases. Bottles and reagents are vitally important resources considering that the first sputum sample must be taken in the office under the supervision and advice of the nurse, this allows better diagnostic opportunities. This result agrees with the literature. [14] and differs from what was found in other studies where training is evaluated as acceptable. [15]. The investigation of respiratory symptoms is the first of the activities to be carried out by family doctors aimed at finding cases to find the largest number of patients and prevent them from infecting new cases. The main cause of non-compliance with this indicator stands out: "the failure to identify vulnerable groups". Failure to comply with the second samples and the culture indicator demonstrate the organizational difficulties in the program and the possibility of timely diagnosis. This result agrees with the literature. [16]. The unfavorable behavior in the treatment of patients could be related to the lack of control of doctors and nurses by not adequately scheduling established field visits to patients, not daily supervising compliance with anti-tuberculosis treatment, or being focused mainly on other activities, in addition to indiscipline on the part of patients who frequently abandon treatments. These results coincide with the literature consulted where the proportion of cured patients was evaluated as not acceptable with ranges that ranged between 60 and $80 \%$. [17, 18]. The loss of follow-up speaks in favor of the indiscipline of the patients when they comply with their treatment, which they abandon, having no 
perception of risk about their disease. The final evaluation of the result dimension was not acceptable as it did not reach the established standard of $80 \%$ of the criteria evaluated as acceptable. The existing gaps in compliance with the tuberculosis control program in the municipality were evaluated as unsatisfactory, this could be due to the lack of material resources, the lack of training of the family doctors and nurses in relation to the program, the failure to investigate vulnerable groups, as well as non-compliance with the essential process indicators in the final results of the program, all this leads to late diagnosis of cases, that is, they are not diagnosed in primary health care. The results obtained in the investigation were compared with similar studies which were also insufficient. [19]

\section{Conclusions}

The lack of human and material resources, the lack of training on the subject, the failure to comply with the diagnostic times, the existence of relapses, loss of follow-up, led to the evaluation of the National Tuberculosis Control Program in the Boyeros municipality, was evaluated as unsatisfactory, since the standards established for each dimension were not met.

\section{References}

[1] Morales Hernández N, Beldarraín Chaple E. The control of tuberculosis in Cuba from the end of the 19th century to 1930. Rev Cubana Med Trop. Jan-Apr 2018; 70 (1): 6-14.

[2] United Nations. The 2030 Agenda and the Sustainable Development Goals: An opportunity for Latin America and the Caribbean. [Internet]. Santiago: Cepal; 2018 [cited 2019 Feb 16]. Available at: https://repositorio.cepal.org/bitstream/handle/11362/40155/24/ S1801141_es.pdf/.

[3] World Health Organization. Global tuberculosis control; surveillance, planning, financing: WHO report. Washington DC: WHO; 2013.

[4] World Health Organization. WHO Report on Tuberculosis [Internet]. Geneva: WHO; 2017 [cited 2018 March 22]. Available https://www.who.int/tb/publications/global_report/gtbr2017_e xecutive_summary_es.pdf?ua $=1$.

[5] Institute of Tropical Medicine. Tuberculosis manual. Tuberculosis Manual Procedures. Procedures for surveillance and control. MINSAP; 2004.

[6] Pan American Health Organization / World Health Organization. Regional Plan for Tuberculosis. 2006-2015. Washington, D.C.: PAHO / WHO; 2006.

[7] National Directorate of Medical Records and Health Statistics. Ministry of Public Health. Statistical Yearbook of Health 2016.

[8] González S, Sauyus C, Pérez R. Evaluation of the tuberculosis surveillance system in the Joaquín Albarrán polyclinic. Rev Cubana Med Gen Integr [Internet]. 2014; 29 (1). Available at: http://scielo.sld.cu/scielo.php?script=sci_arttext\&pid=S08642

\section{$1252013000100011 \&$ nrm=iso.}

[9] Alvarez LE, Pérez E J, Góez JD, Rivera A, Peña C. Methods for evaluating large-scale nutritional programs in Latin America: an integrative review. Nutr Hosp. 2015; 31: 143-54.

[10] García A CA, Muñoz AI. Evaluation of programmatic indicators: the need for a social approach to tuberculosis. Journal of the National School of Public Health [Internet]. 2014 [cited 2019 April 16]; [approx. 4 p.]. Available at: http://search.ebscohost.com/login.aspx?direct $=$ true \&db=a9h\& $\mathrm{AN}=99716461 \&$ lang $=$ es\&site $=$ ehost-live.

[11] Rosado S, Godínez L, Ranero V. Evaluation of the National Tuberculosis Control Program in Bauta. Rev Cubana Hig Epidemiol [Internet] Jan.-Apr 2014 [cited Apr 22, 2018]; 52 (1): 98-105. Available at: http://search.ebscohost.com/login.aspx?direct=true $\& \mathrm{db}=1$ th $\&$ $\mathrm{AN}=102183800 \&$ lang=es\&site $=$ ehost-live. Tuberculosis pulmonar En: NIH. Biblioteca Médica de los Estados Unidos. Medline Plus [Internet]. Bethesda, U.S.: U.S National Library of Medicine; 2018 [citado 16 Feb 2018] [aprox. 4 p.].

[12] Pulmonary tuberculosis In: NIH. United States Medical Library. Medline Plus [Internet]. Bethesda, U.S.: U.S National Library of Medicine; 2018 [cited Feb 16, 2018] [approx. 4 p.]. Available https://medlineplus.gov/spanish/ency/article/000077.htm.

[13] Beldorin H. Quality in the execution of the national tuberculosis control program [Thesis]. City of Santiago de Cuba: University of Medical Sciences Faculty of Medicine 1; 2014 [cited 8 Aug 2018]. Available at: http://www.scielo.org.co/pdf/inf/v20n3/v20n3a06.pdf.

[14] Duarte Rodríguez B, López Díaz2018] [approx. 4 p.]. Available https://medlineplus.gov/spanish/ency/article/000077.htm.

[15] Duarte Grandales S, Toledano Grave de Peralta Y, Lafargue Mayoz D, from Campo Mulet E, Cuba García M. Quality of the execution of the National Tuberculosis Control Program at the "José Martí" University Polyclinic. MEDISAN [Internet]. May 2013 [cited March 21, 2019]; 14 (5): [approx. 5 p.]. Available at: http://search.ebscohost.com/login.aspx?direct=true $\& \mathrm{db}=\mathrm{a} 9 \mathrm{~h} \&$ AN=87522014\&lang=es\&site=ehost-live.

[16] Estévez Estévez Y, Ruiz Sánchez R, Vázquez García I, Soto Paz J. Evaluation of process, outcome and impact indicators of the tuberculosis program in Guantánamo. Scientific Information Magazine [Internet]. 2015 [cited 22 Mar 2018]; 91 (3): [approx. 9 p.]. Available at: http://web.a.ebscohost.com/ehost/pdfviewer/pdfviewer?Vid=2 $0 \&$ sid=f753dcf9-3121-45ec-bdbe-fd49ff9bed 78\%40sessionm gr4009.

[17] Paneque Rodríguez L, Valle Plous A, Oliva Martínez M. Indicators of the National Tuberculosis Control Program in San José de las Lajas. Medi Magazine May 2017; 24 (3).

[18] Cassiano T, Prestesleal F. Co-Infection with Mycobacterium Tuberculosis (TB) and Human Immunodeficiency Virus (HIV / AIDS) in Patients of the Sarandi City, Paraná State, Brazil. Brazilian Journal of Surgery and Clinical Research. Mar-Mai 2015; 10 (1): 21-26.

[19] Duarte Rodríguez B, López Díaz S, Gallardo Pons G, Cabrera Torres O, Pérez Castillo JM. Evaluation of the Tuberculosis Program in closed institutions. Rev. Medical Sciences. March-April 2015; 19 (2): 253-265. 